\title{
Conservative compensatory Angle Class III malocclusion treatment
}

\author{
Marcio Costa Sobral', Fernando Antônio de Lima Habib², Liz Matzenbacher ${ }^{3}$
}

\begin{abstract}
Introduction: Angle's Class III malocclusion is a dental discrepancy in a sagittal view that may appear or not with an important skeletal discrepancy. Facial esthetics may be affected by this skeletal discrepancy and it is one of the most common complaints of patients who seek orthodontic treatment. Class III treatment, in adults, may be done by compensatory tooth movement, in simple cases, or through an association between orthodontics and orthognathic surgery, in more severe cases. Objective: This article describes a non-extraction compensatory Class III treatment case, applying the Tweed-Merrifield mechanical principles with headgear (J-Hook) in the mandibular arch. This case was presented at the V Brazilian Association of Orthodontics and Dentofacial Orthopedics (ABOR) Meeting, it was evaluated by members of Brazilian Board of Orthodontics and obtained third place in the general classification.
\end{abstract}

Keywords: Angle's Class III malocclusion. Corrective orthodontics. Extraoral traction appliances.

Introdução: a má oclusão de Classe III se caracteriza por uma desarmonia dentária anteroposterior, podendo estar ou não acompanhada por discrepâncias esqueléticas. A estética facial pode se apresentar comprometida, em maior ou menor grau, a depender da magnitude da discrepância, constituindo um dos principais fatores motivadores da procura por tratamento ortodôntico. O tratamento da Classe III em pacientes adultos pode ser realizado mediante compensação dentária, nos casos mais simples, ou, em situações mais severas, mediante a associação entre Ortodontia e Cirurgia Ortognática. Objetivo: o presente artigo objetiva relatar um caso clínico caracterizado por uma má oclusão de Classe III de Angle, tratado de forma compensatória, com extração dos terceiros molares inferiores, mediante a utilização de aparelhagem extrabucal na arcada inferior (J-hook), aplicando-se princípios da técnica de Tweed-Merrifield. Esse caso foi apresentado no $5^{\circ}$ Congresso da Associação Brasileira de Ortodontia e Ortopedia Facial (ABOR), na categoria “mesa clínica”, sendo avaliado por membros do Board Brasileiro de Ortodontia e Ortopedia Facial (BBO) e obtendo o terceiro lugar na classificação geral.

Palavras-chave: Má oclusão de Angle Classe III. Ortodontia corretiva. Aparelhos de tração extrabucal.

${ }^{1}$ Professor of the Specialization Course in Orthodontics, Federal University of Bahia (UFBA). Diplomate by the Brazilian Board of Orthodontics (BBO).

${ }^{2}$ Adjunct Professor of Orthodontics, Federal University of Bahia (UFBA).

${ }^{3}$ Specialist in Orthodontics, UFBA.

Contact address: Marcio Costa Sobral

Av. Anita Garibaldi, 1815 - Sala 315B - Ondina - Salvador/BA - Brazil

E-mail:marciosobral@gmail.com
How to cite this article: Sobral MC, Habib FAL, Matzenbacher L. Conservative compensatory Angle Class III malocclusion treatment. Dental Press J Orthod. 2012 Nov-Dec;17(6):137-45.

Submitted: July 18, 2009 - Revised and accepted: November 30, 2010

» The author reports no commercial, proprietary or financial interest in the products or companies described in this article.

» Patients displayed in this article previously approved the use of their facial and intraoral photographs. 


\section{HISTORY AND ETIOLOGY}

The 13-year-old patient, in good general health, presented for initial examination at the Center of Orthodontics and Facial Orthopedics Professor José Édimo Soares Martins of the School of Dentistry of the Federal University of Bahia (UFBA). Her medical history showed a record of mumps, measles and chickenpox that had occurred in her childhood. She did not have any abnormal blood pressure. Her main complaint was related to the presence of anterior crossbite and ectopic eruption of tooth 13. Despite protrusion of the lower lip and little exposure of the upper lip, facial esthetics did not seem to be a concern to the patient (Fig 1). A more detailed examination of occlusion showed the presence of premature contact of the incisors, in a centric relation, leading to a more anterior position of the mandible in centric occlusion. Her mother had reported no Class III malocclusion family history, so, the peculiarities involved in this case point to a multifactorial etiology.

\section{DIAGNOSIS}

The patient presented significant skeletal discrepancy with $\mathrm{ANB}$ angle equal to $-3^{\circ}$, $\left(\mathrm{SNA}=82^{\circ}\right.$ and $\mathrm{SNB}=85^{\circ}$ ), with good vertical mandibular growth direction $\left(\mathrm{SN}-\mathrm{GoGn}=31^{\circ}\right)$ in a predominantly horizontal direction $\left(\mathrm{SNB}=85^{\circ}\right)$. The maxilla was well positioned in relation to the cranial base $\left(\mathrm{SNA}=82^{\circ}\right)$. These observations may be better evaluated in Figure 6.
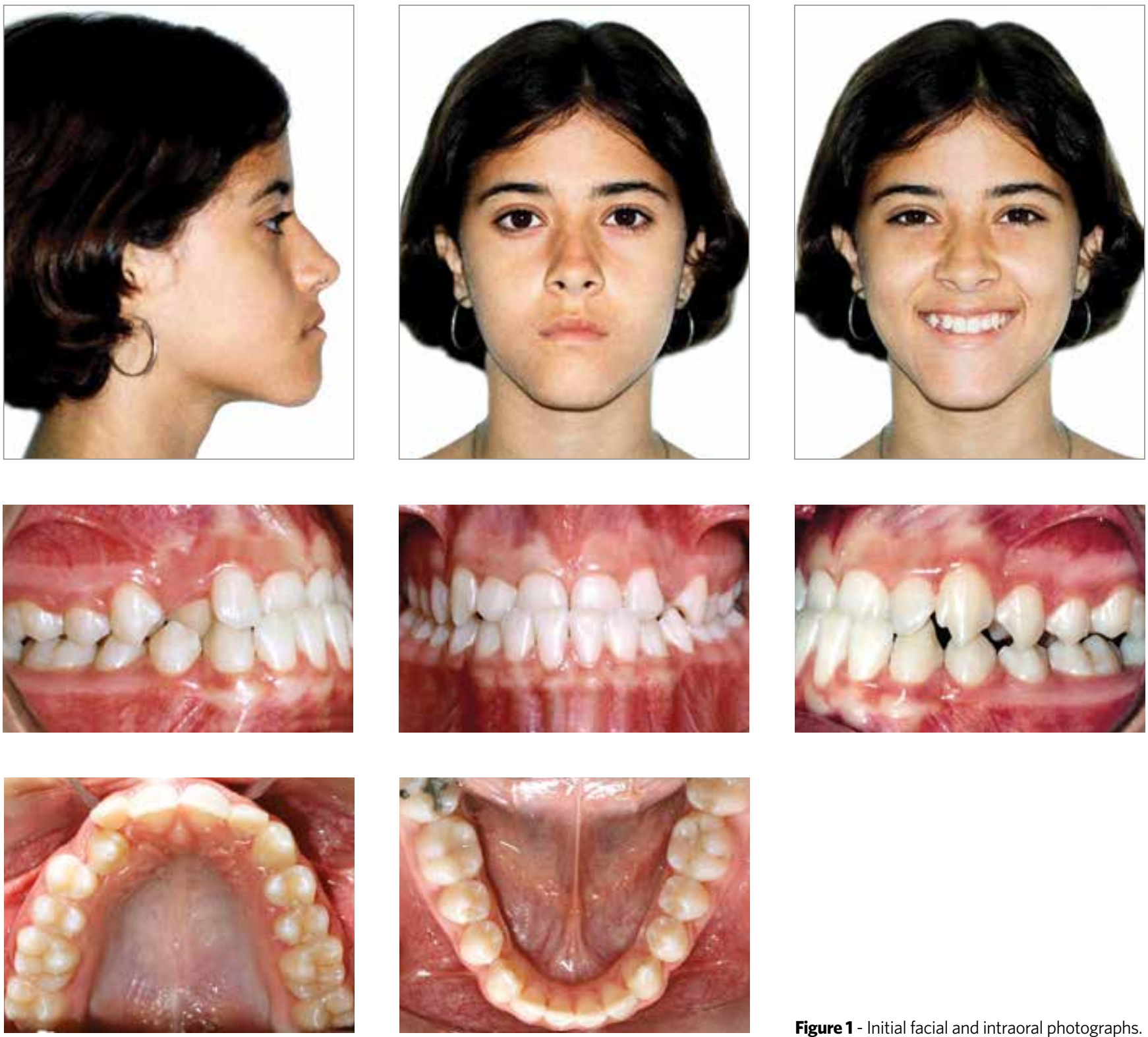

Figure 1 - Initial facial and intraoral photographs. 
With regard to the tooth aspect, the patient presented Angle's Class III malocclusions with anterior crossbite, $1 \mathrm{~mm}$ overjet, $50 \%$ overbite and retroinclined mandibular and maxillary incisors. When handling the mandible in centric relation, premature contact was found in the incisor region which led to functional deviation in the anterior direction that accentuated the Class III malocclusion. Furthermore, moderate anterior-superior crowding, tooth 13 in palato-version, and the mandibular and maxillary midlines coinciding with each other were also found (Figs 1 and 2). When analyzing the facial characteristics, the patient presented a mesocephalic face with a concave profile, proportional facial thirds, lip competence, and absence of significant asymmetries. The lower lip was slightly more protrusive than the upper lip (Fig 1).

The analysis of the periapical and panoramic radiographs (Fig 3) did not show any significant alteration that would be contraindication to orthodontic treatment (Fig 3).

The radiographic analysis of the hand and wrist suggested end of pubertal growth spurt with complete welding of the epiphysis and diaphysis as well as total sesamoid ossification (Fig 4).
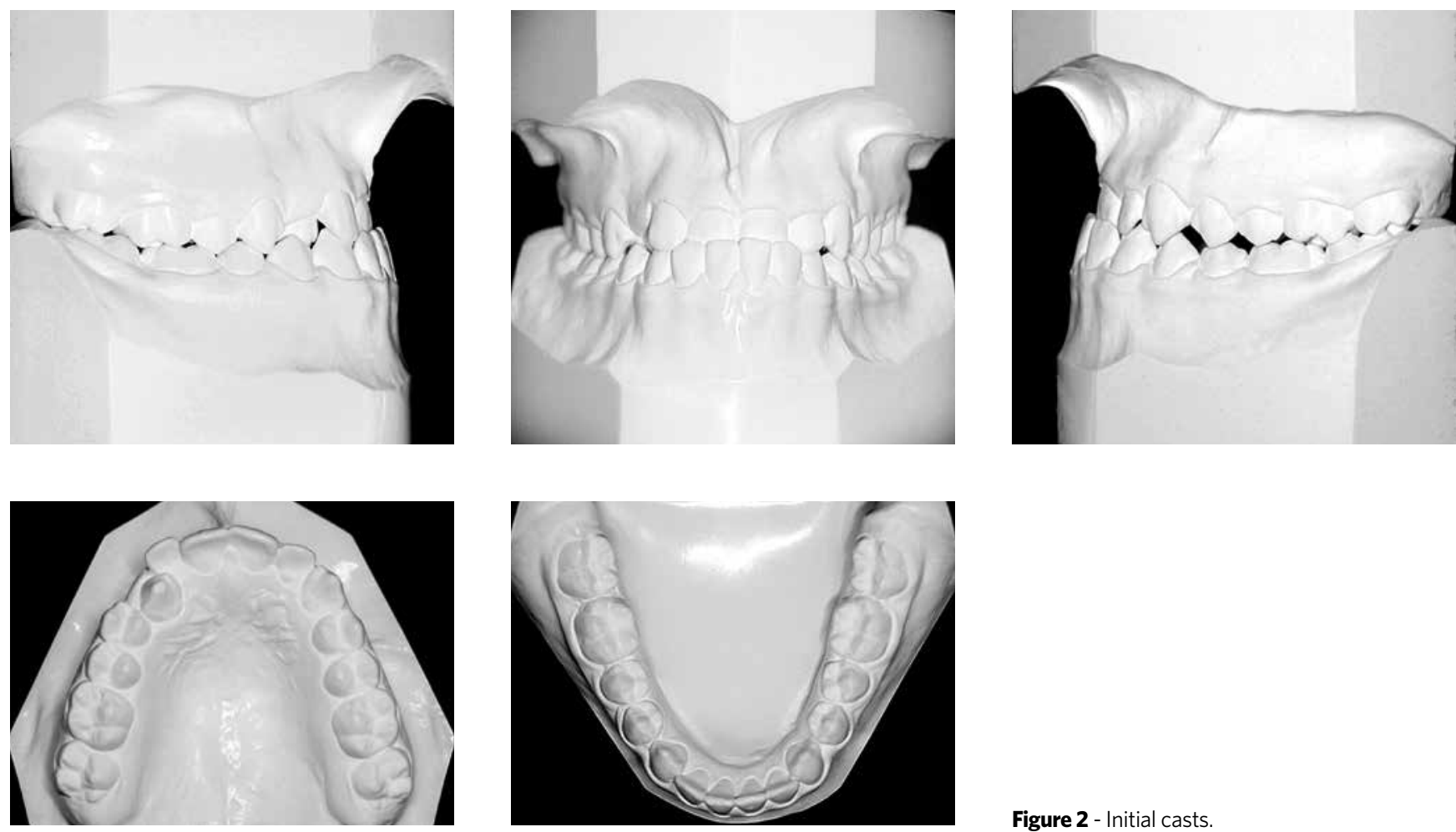

Figure 2 - Initial casts.

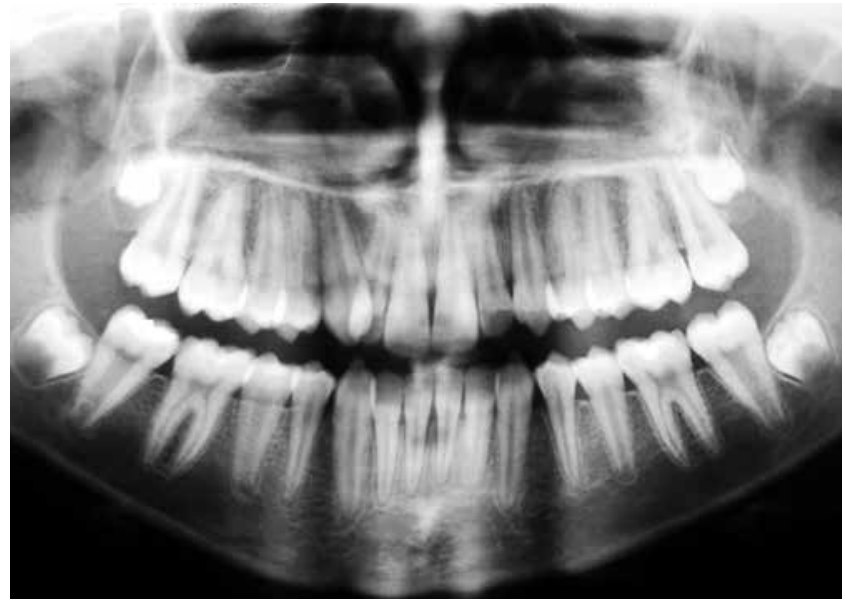

Figure 3 - Initial panoramic radiograph.

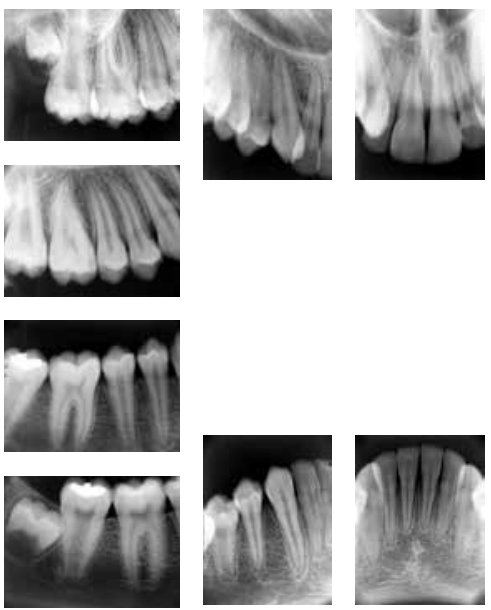

Figure 4 - Initial periapical radiographs.
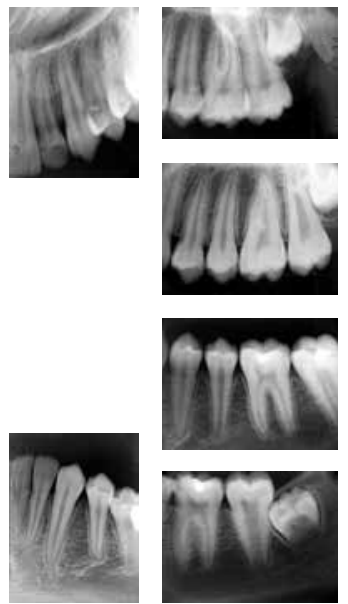


\section{OBJECTIVES OF THE TREATMENT}

The objective of treatment was to release constrained growth of the maxilla due to anterior crossbite by changing the axial inclination of the incisors and to promote transversal expansion in order to improve arch shape by providing adequate space to move the right canine into position.

In the mandible the objective was to maintain the position of the basal bone, establish occlusal relationship of the first molars by distalizing the mandibular teeth, keep the occlusal plane, and promote effective vertical control. Thus, significant improvement in the dental pattern was expected with a direct impact on the smile, but without major changes in facial appearance.

\section{TREATMENT PLAN}

Two treatment plans were prepared. The first one consisted of waiting for the end of the growth phase in order to begin combined orthodontic-surgical treatment. The patient and her parents were strongly against the surgical alternative and inquired if there was any other possibility. The other option was orthodontic camouflage. In the event of a considerable residual mandibular growth during compensatory treatment, the surgical alternative would be the only feasible option. In view of the above-mentioned, her parents opted for the compensatory treatment for Class III malocclusion.

At first, expansion of the maxillary arch using the Haas expander and extraction of mandibular third molars were planned. Next complete fixed compensatory orthodontic treatment was performed (orthodontic camouflage) with Class III mechanics supported by a high-pull headgear, similar to the J-Hook headgear, that was directly adapted to the sliding jigs in the mandibular arch with the purpose of distalizing mandibular teeth individually (modified TweedMerrifield technique). After maxillary expansion, alignment and leveling was performed using sequential archwires (0.014 to 0.020-in) and proclination of anterior teeth. Afterwards ideal mandibular and maxillary archwires measuring 0.019 x 0.026-in would be fabricated with ideal bends and torques for finishing. A wrap-around-type plate would be placed in the maxillary arch for retention and an intercanine bar with a 0.028-in wire in the mandibular arch.

\section{TREATMENT PROGRESS}

The modified Haas expander device was used in the maxillary arch with bands on the first premolars and molars that were also encapsulated in the posterior region. Standard metal brackets were then bonded without torque or angulation using the $0.022 \times 0.028$-in slot edgewise system. In the mandibular arch, in addition to the fixed appliance, a J-Hook high-pull headgear was used.

Expansion occurred after activation at a rate of two-quarter turns a day for 15 days. After the active period, the screw was immobilized and the appliance was kept for retention for 6 months. During this period, the fixed appliance was bonded on the incisors and maxillary canines and the teeth were aligned and leveled. After the Haas device was removed, the other maxillary teeth were bonded to obtain alignment and leveling using archwires measuring 0.014-in, 0.016-in, 0.018-in, 0.020-in, in sequence. Given the good configuration of the mandibular arch in relation to alignment and leveling, $0.019 \times 0.025$-in archwires were placed, with little compensation, and tip-back bends in the teeth 37 and 47 and hooks welded between teeth 32-33 and 42-43. These hooks were used to support the J-Hooks (250 g force on each side) with cervical traction. With the tip-back bends potentiated by the use of the headgear, teeth 37 and 47 were uprighted creating a space of approximately $2 \mathrm{~mm}$ on each side between teeth 37 and 47 and the adjacent teeth 36 and 46, respectively. Then stops were welded tightly fit to the accessories of these teeth with the purpose of maintaining the space obtained. Using extraoral force associated with the sliding jigs, the posterior-inferior segments were distalized until adequate intercuspation was obtained. Rectangular and coordinated arches, measuring $0.019 \times 0.025$-in, with ideal shape and torque were used for finishing. After achieving all the treatment objectives, the retention phase began by fabricating a removable maxillary plate (wrap-around) and bonding a mandibular intercanine bar made of 0.028 -in round wire. The patient was instructed to use the plate for 24 hours a day during the first 6 months, 18 hours a day for the following 6 months, 12 hours a day for 6 more months, and finally only at night. 


\section{TREATMENT EVALUATION}

The main objectives of treatment were achieved taking into account that residual growth presented during treatment was favorable for the success of orthodontic camouflage. Due to dental alterations, significant change in the ANB angle from $-3^{\circ}$ to $1^{\circ}$ was achieved (Fig 11). This may be attributed to the significant improvement in the inclination of maxillary incisors with an increase in the 1-NA angle from $17^{\circ}$ to $28^{\circ}$ directly resulting in an increase of the SNA angle of 4 degrees and the SNB angle remaining stable (Table 1, Figs 11 and 12).
The occlusal relationship of canines and molars, correction of anterior crossbite, alignment and leveling, and the inclusion of tooth 13 in the arch were obtained. Alignment, leveling, correction of misalignments and inclination were all successfully achieved (Figs 7 and 8). Significant improvement in the esthetics of the smile was obtained, but no significant changes were observed in the profile since it was a Class III compensatory treatment, in which the main objective was to improve the dental relationship. At the end of treatment, extraction of the maxillary third molars was required.

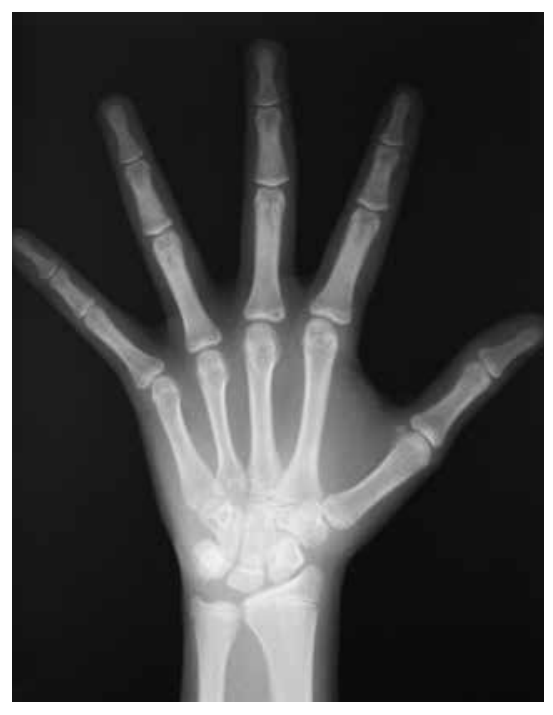

Figure 5 - Hand and wrist radiograph.

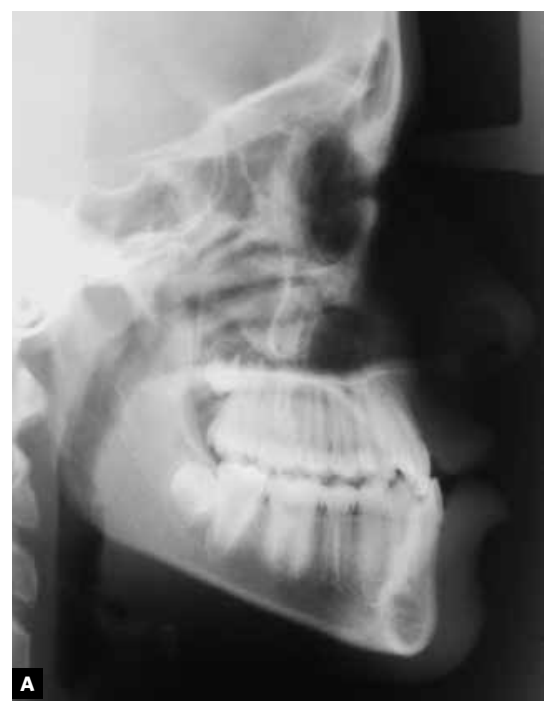

Figure 6 - Lateral cephalometric radiograph (A) and initial cephalometric tracings (B). 

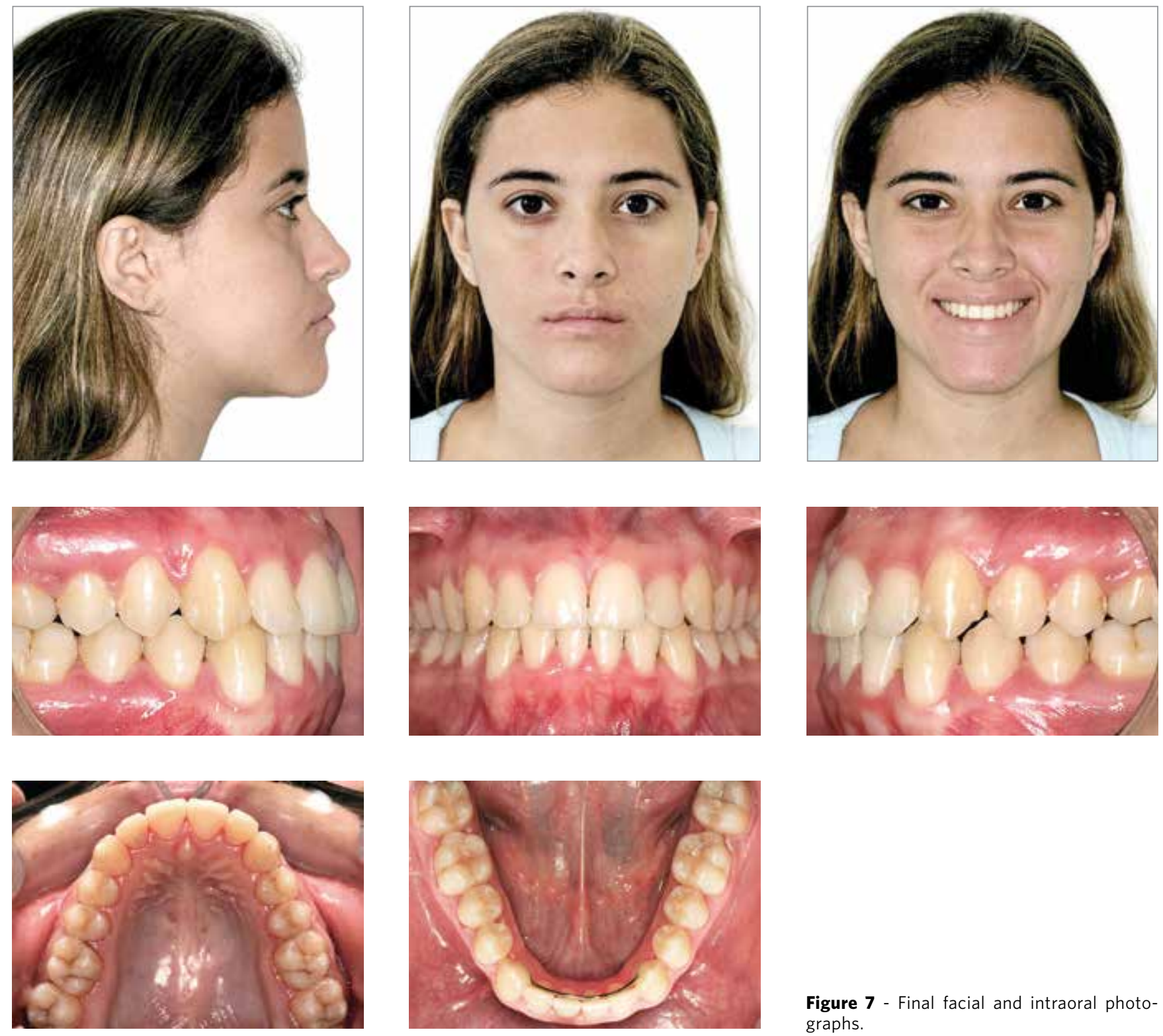

Figure 7 - Final facial and intraoral photographs. 

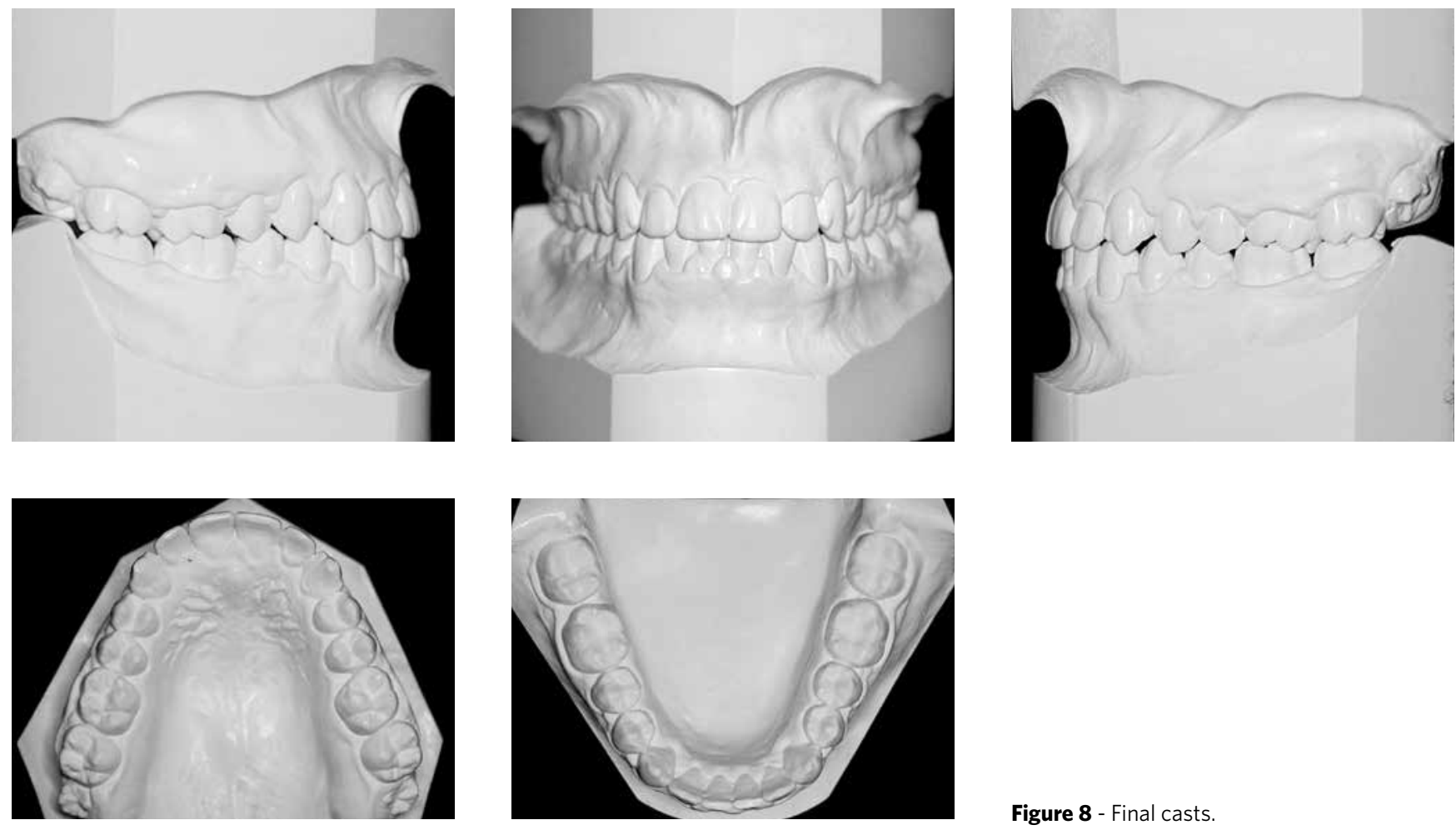

Figure 8 - Final casts.

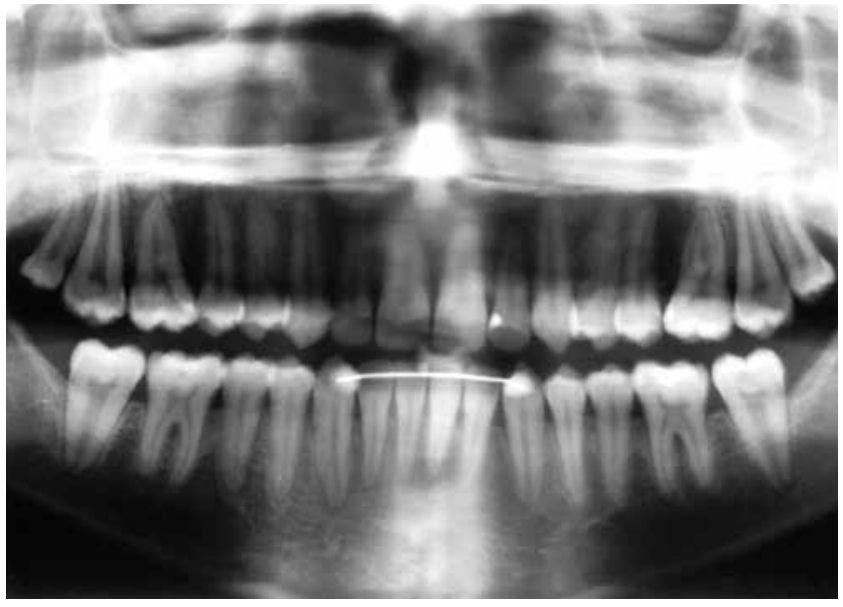

Figure 9 - Final panoramic radiograph.
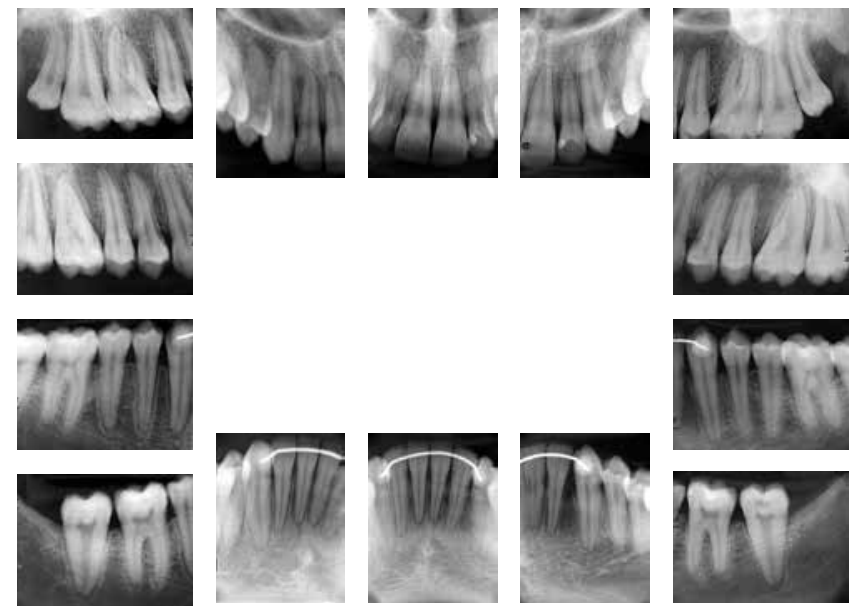

Figure 10 - Final periapical radiographs. 
Table 1 - Summary of cephalometric measurements.

\begin{tabular}{|c|c|c|c|c|c|}
\hline & MEASUREMENTS & Normal & Initial (A) & Final (B) & A - B difference \\
\hline \multirow{8}{*}{ Skeletal pattern } & SNA (Steiner) & $82^{\circ}$ & $82^{\circ}$ & $86^{\circ}$ & 4 \\
\hline & SNB (Steiner) & $80^{\circ}$ & $85^{\circ}$ & $85^{\circ}$ & 0 \\
\hline & ANB (Steiner) & $2^{\circ}$ & $-3^{\circ}$ & $1^{\circ}$ & 4 \\
\hline & Angle of convexity (Downs) & $0^{\circ}$ & $-7^{\circ}$ & $-2^{\circ}$ & 5 \\
\hline & Y axis (Downs) & $59^{\circ}$ & $63^{\circ}$ & $64^{\circ}$ & 1 \\
\hline & Facial angle (Downs) & $87^{\circ}$ & $93^{\circ}$ & $94^{\circ}$ & 1 \\
\hline & SN.GoGn (Steiner) & $32^{\circ}$ & $31^{\circ}$ & $31^{\circ}$ & 0 \\
\hline & FMA (Tweed) & $25^{\circ}$ & $22^{\circ}$ & $22^{\circ}$ & 0 \\
\hline \multirow{7}{*}{ Dental pattern } & IMPA (Tweed) & $90^{\circ}$ & $82^{\circ}$ & $86^{\circ}$ & 4 \\
\hline & 1.NA (degrees) (Steiner) & $22^{\circ}$ & $17^{\circ}$ & $28^{\circ}$ & 11 \\
\hline & 1-NA (mm) (Steiner) & $4 \mathrm{~mm}$ & $5 \mathrm{~mm}$ & $7 \mathrm{~mm}$ & 2 \\
\hline & T.NB (degrees) (Steiner) & $25^{\circ}$ & $18^{\circ}$ & $21^{\circ}$ & 3 \\
\hline & $\overline{1}-\mathrm{NB}(\mathrm{mm})$ (Steiner) & $4 \mathrm{~mm}$ & $3 \mathrm{~mm}$ & $5 \mathrm{~mm}$ & 2 \\
\hline & $\underline{1} .1$ - Interincisal angle (Downs) & $130^{\circ}$ & $148^{\circ}$ & $131^{\circ}$ & 17 \\
\hline & 1-APo (mm) (Ricketts) & $1 \mathrm{~mm}$ & $4 \mathrm{~mm}$ & $2 \mathrm{~mm}$ & 2 \\
\hline \multirow{2}{*}{ Profile } & Upper lip - S line (Steiner) & $0 \mathrm{~mm}$ & $-2 \mathrm{~mm}$ & $-2 \mathrm{~mm}$ & 0 \\
\hline & Lower lip -S line (Steiner) & $0 \mathrm{~mm}$ & $3 \mathrm{~mm}$ & $0 \mathrm{~mm}$ & 3 \\
\hline
\end{tabular}
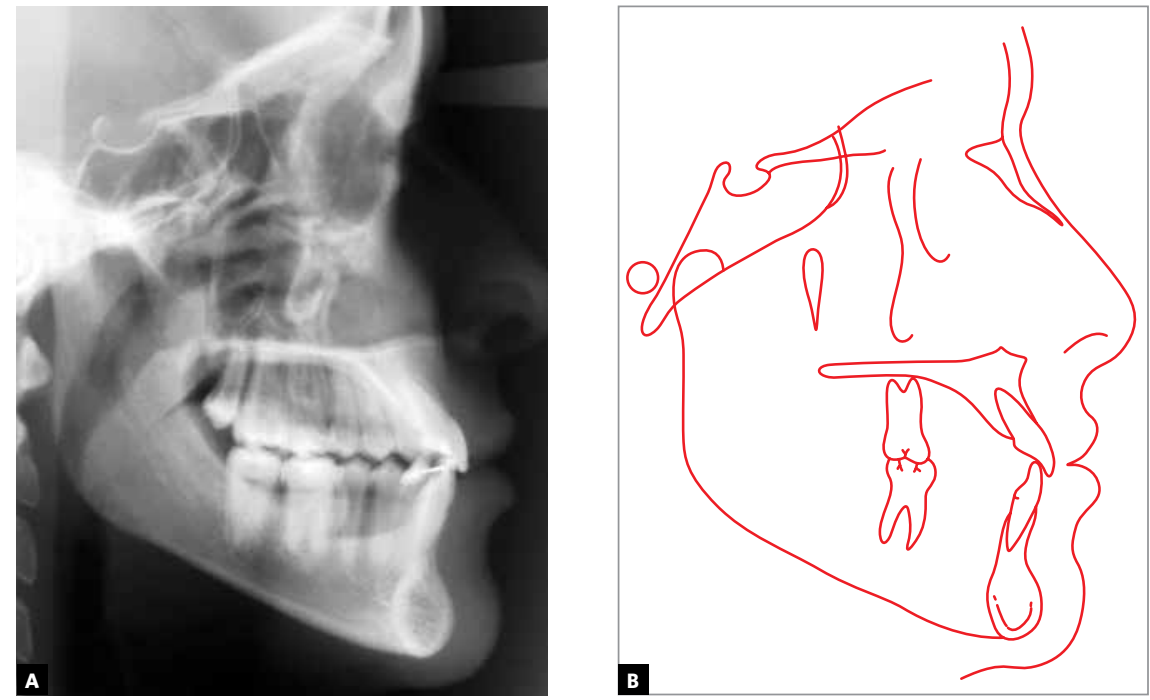

Figure 11 - Lateral cephalometric radiograph (A) and final cephalometric tracings (B).

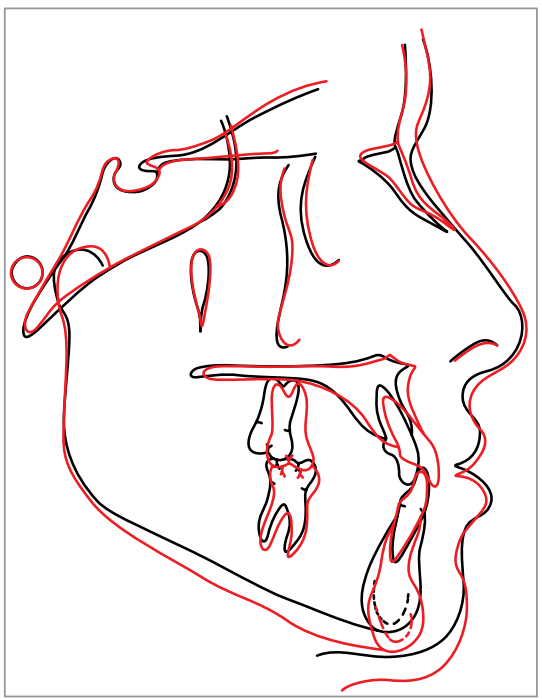

Figure 12 - Total superimposition of initial and final tracings. 


\section{FINAL CONSIDERATIONS}

The presence of Angle's Class III malocclusion associated with skeletal maxillomandibular discrepancy is a difficult problem in Orthodontics. Depending on the magnitude of this discrepancy and the degree of impairment of facial esthetics, this problem may have negative psychological consequences in the social life of the individual, in addition to functional implications directly related to the stomatognathic system.

Orthodontics has several resources in for treating Class III malocclusions, ranging from beginning treatment in young individuals up to surgical-orthodontic treatment in adults. As a third alternative, in certain cases, the compensatory orthodontic treatment, also known as orthodontic camouflage, may be applied with the purpose of providing satisfactory occlusion through dental compensations, but with minor changes in facial esthetics.

In the case described, the 13-year-old patient, who presented signs of advanced skeletal maturation (hand and wrist radiographs, secondary sexual characteristics), decided with her parents to take the risks of immediately initiating camouflage orthodontic treatment, although she had been informed of the benefits of combined surgical orthodontic treatment to be performed at a later stage. The absence of family history with similar discrepancies was an important fact that influenced the therapeutic decision-making.

Treatment was conducted without extractions, with expansion of the maxillary arch and extra-oral mechanics acting directly on the mandibular arch in order to distalize the mandibular teeth correcting Class III malocclusion and establishing adequate intercuspation without side effects in the maxillary arch by applying the modified technique described by Merrifield-Tweed. With the expansion of the maxillary arch and subsequent projection of the incisors, anterior crossbite was corrected while, at the same time, it was possible to establish the occlusal relationship of the first molars and canines in the mandibular arch and obtain adequate levels of overbite and overjet by using a J-Hook headgear with cervical traction. By correcting the anterior crossbite, significant improvement in the esthetics of the smile was obtained.

During and after completion of treatment, no unfavorable residual mandibular growth was found, which was of utmost importance for the success of the orthodontic camouflage treatment in this particular case.

\section{REFERENCES}

1. Ellis E, McNamara JA. Components of adult Class III malocclusion. Am J Oral Maxillofac Surg. 1984;42(5):295-305

2. Merrifield L. Edgewise sequential directional force technology. J Charles H. Tweed Found. 1986;14:22-37

3. Ngan P, Wei SH, Hagg U, Yiu CK, Merwin D, Stickel B. Effect of protraction headgear on Class III malocclusion. Quintessence Int. 1992;23(3):197-207.

4. Turley PK. Orthopedic correction of Class III malocclusion with palatal expansion and custom protraction headgear. J Clin Orthod. 1988;22(5):314-25. 